\title{
Ribozyme-mediated reduction of wild-type and mutant cartilage oligomeric matrix protein (COMP) mRNA and protein
}

\author{
JOSEPH L. ALCORN, ${ }^{1,4}$ THOMAS M. MERRITT, ${ }^{1,4}$ MARY C. FARACH-CARSON, ${ }^{2}$ HUIQUI H. WANG, \\ and JACQUELINE T. HECHT ${ }^{1,3}$ \\ ${ }^{1}$ The Department of Pediatrics, The University of Texas Medical School at Houston, Houston, Texas 77030, USA \\ ${ }^{2}$ Department of Biology, University of Delaware, Newark, Delaware 19716, USA \\ ${ }^{3}$ Shriners Hospital for Children, Houston, Texas 77030, USA
}

\begin{abstract}
Dominant-negative mutations in the homopentameric extracellular matrix glycoprotein cartilage oligomeric matrix protein (COMP) result in inappropriate intracellular retention of misfolded COMP in the rough endoplasmic reticulum of chondrocytes, causing chondrocyte cell death, which leads to two skeletal dysplasias: pseudoachondroplasia (PSACH) and multiple epiphyseal dysplasia (EDM1). COMP null mice show no adverse effects on normal bone development and growth, suggesting a possible therapy involving removal of COMP mRNA. The goal of this study was to assess the ability of a hammerhead ribozyme (Ribo56, designed against the D469del mutation) to reduce COMP mRNA expression. In COS7 cells transfected with plasmids that overexpress wild-type or mutant COMP mRNA and Ribo56, the ribozyme reduced overexpressed normal COMP mRNA by 46\% and mutant COMP mRNA by $56 \%$ in a dose-dependent manner. Surprisingly, the use of recombinant adenoviruses to deliver wild-type or mutant COMP mRNA and Ribo56 simultaneously into COS7 cells proved problematic for the activity of the ribozyme to reduce COMP expression. However, in normal human costochondral cells (hCCCs) infected only with adenoviruses expressing Ribo56, expression of endogenous wild-type COMP mRNA was reduced in a dose-dependent manner by $50 \%$. In chondrocytes that contain heterozygous COMP mutations (D469del, G427E and D511Y) that cause PSACH, Ribo56 was more effective at reducing COMP mRNA (up to $70 \%$ ). These results indicate that Ribo56 is effective at reducing mutant and wild-type COMP levels in cells and suggests a possible mode of therapy to reduce the mutant protein load.
\end{abstract}

Keywords: PSACH; ribozyme; gene therapy; adenovirus; chondrocyte

\section{INTRODUCTION}

Cartilage oligomeric matrix protein (COMP/TSP-5) is one of the proteins that comprise the complex extracellular matrix (ECM) networks of cartilage, tendon, and ligament that cushion and stabilize skeletal elements (Kempson et al. 1968; Urban et al. 1979; Schmidt et al. 1990). COMP, the fifth member of the thrombospondin (TSP) gene family, is a multidomain homopentameric protein comprised of an $\mathrm{N}$-terminal pentamerization domain, an epidermal growth factor (EGF)-like domain, a highly conserved type 3 (calcium-binding) repeat domain, and a C-terminal globular region (Fife and Brandt 1984; DiCesare et al. 1994;

\footnotetext{
${ }^{4}$ These authors contributed equally to this work.

Reprint requests to: Jacqueline T. Hecht, Department of Pediatrics, The University of Texas Medical School at Houston, P.O. Box 20708, Houston, TX 77030, USA; e-mail: Jacqueline.T.Hecht@uth.tmc.edu; fax: (713) 500-5689. Article published online ahead of print. Article and publication date are at http://www.rnajournal.org/cgi/doi/10.1261/rna.1335909.
}

Adams et al. 1995; Smith et al. 1997; Hecht et al. 1998a; Carlson et al. 2008). Recent work suggests that COMP is multifunctional and is involved in (1) regulation of collagen fiber assembly/diameter (Rosenberg et al. 1998); (2) interaction with other ECM molecules (Holden et al. 2001; Thur et al. 2001; Mann et al. 2004); (3) regulation of chondrocyte proliferation (Kipnes et al. 2003; Xu et al. 2007); (4) regulation of apoptosis (Duke et al. 2003; Hashimoto et al. 2003; Hecht et al. 2004); and (5) enhancement of cellular attachment (Chen et al. 2005).

Mutations in COMP cause two skeletal dysplasias: a severe disproportionate dwarfing condition, pseudoachondroplasia (PSACH), and a milder condition, multiple epiphyseal dysplasia (MED/EDM1 subtype) (Briggs et al. 1995; Hecht et al. 1995; Thur et al. 2001; Briggs and Chapman 2002). PSACH is a dwarfing condition in which infants have a normal birth length and weight and are first diagnosed when their linear growth decelerates between 1 and 2 years of age 
(Unger and Hecht 2001; Posey et al. 2004). Characteristic PSACH clinical findings include waddling gait beginning in early childhood; widened and lax joints; brachydactyly; windswept, knock knee, or bowing deformities of the lower extremities; exaggerated lumbar lordosis; and early onset osteoarthritis (Unger and Hecht 2001; Posey et al. 2004). Replacement of the weight-bearing joints, particularly knees and hips, often is required in early adulthood (Unger and Hecht 2001). In contrast to PSACH, MED is diagnosed around five years of age when the children present with abnormal gait and/or stiff painful hips (Unger and Hecht 2001). Mild short stature and osteonecrosis of the hips (Legg-Perthes disease) are also frequent findings in MED (Unger and Hecht 2001). Hip replacement often is needed in early adulthood (Unger and Hecht 2001).

More than 100 novel COMP mutations have been identified, with the majority found in the highly conserved type 3 calcium-binding repeat domain (Briggs et al. 1995; Hecht et al. 1995; Unger and Hecht 2001; Kennedy et al. 2005). The most common mutation, D469del, accounts for $\sim 30 \%$ of all PSACH cases (Unger and Hecht 2001; Kennedy et al. 2005). These mutations produce a COMP molecule consisting of a mixture of mutant and wild-type subunits that causes protein stalling in the rER and intracellular COMP accumulation in large rER cisternae (Cooper et al. 1973; Hecht et al. 1998b, 2005; Chen et al. 2004). This massive intracellular protein retention eventually leads to chondrocyte death; the loss of chondrocytes translates into markedly diminished linear growth in affected individuals (Unger and Hecht 2001; Briggs and Chapman 2002).

Transgenic mouse models expressing mutant COMP demonstrate a mild PSACH phenotype (Pirog-Garcia et al. 2007; Schmitz et al. 2007; Posey et al. 2008). In contrast, COMP knockout mice develop normally, suggesting that COMP may not be necessary or has a redundant function in cartilage formation, bone growth, and extracellular cartilage matrix (ECM) development (Svensson et al. 2002). These observations led to the hypothesis that elimination of a majority of the mutant COMP from the secretory pathway would prevent the cellular pathology associated with the PSACH phenotype without side effects owed to partial reduction of its normal counterpart. RNAi (interference) technology is one approach that could be used to reduce in vitro and in vivo gene expression.

Ribozymes are short catalytic RNA oligonucleotides that either splice or cleave RNA molecules and were hailed in the early years of gene therapy research for their potential to control gene expression (Cameron and Jennings 1989; Haseloff and Gerlach 1992; McCall et al. 1992; James and Turner 1997). However, interest in ribozymes faded when they did not reliably knock down targeted genes and with the advent of siRNA technologies. Recently, there has been a renewed interest in the use of ribozymes as a means to knock down expression of specific genes because of recent advances in design and delivery, better stabilization, and their ability to remain active over long periods in vivo. Hammerhead ribozymes are small ribozymes consisting of 24-35 nucleotides and three stem-loop structures that induce a site-specific cleavage of RNA based on WatsonCrick base pairing with their target sequences (Haseloff and Gerlach 1988; Ruffner et al. 1990; Shimayama et al. 1995). Because the hammerhead ribozyme functional sequence is short and conserved, novel designs can quickly be synthesized and tested in cell culture for knockdown of mRNA expression of genes that cause disease (Hendry et al. 1997; Tabler and Sczakiel 1997; Blount and Uhlenbeck 2002; Liu et al. 2002; Khan 2006). In addition, ribozymes, unlike siRNA, are not thought to activate interferon responses (Shiota et al. 2004), so they may have longer-term utility in whole animal/humans. These studies were undertaken to test the efficacy and potential utility in gene therapy applications of a novel ribozyme targeting COMP.

\section{RESULTS}

\section{COMP-specific ribozyme (Ribo56) reduces steady-state levels of wild-type COMP mRNA or mutant COMP (D469del) mRNA and protein in transfected COS7 cells}

To determine whether Ribo56 can reduce steady-state wildtype (WT) and mutant (MT) COMP mRNA in cells, COS7 cells were transfected with plasmids that express WT-COMP (pWT-COMP) or MT-COMP (pMT-COMP). Since these cells do not express COMP or other cartilage-specific ECM proteins (Hashimoto et al. 2003), all of the WT and MTCOMP mRNA assessed in these studies was expressed from the plasmids. Cells were cotransfected with increasing amounts $(0 \times-32 \times)$ of a plasmid that express Ribo56 (pRibo56). Transfection efficiency in COS7 cells was consistently found to be $30 \%-35 \%$ (data not shown). RNA and protein were isolated 72 -h post-transfection and subjected to Northern and Western analysis. Northern analysis of WT and MT-COMP mRNA (shown in Fig. 1A) indicates that Ribo56 decreased steady-state levels of WT- and MT-COMP mRNA in a dose-dependent manner. The reduction in mRNA expression is significant $(P<0.05)$ for Ribo56 at concentrations of 8,16 , and $32 \times$ compared with RNA levels without Ribo56 (Fig. 1A). The most efficient knockdown of COMP mRNA occurred at $32 \times$ Ribo56, with $46 \%$ reduction of WTCOMP mRNA and 56\% reduction of MT-COMP mRNA levels. Importantly, Ribo56 had comparable activity against WT- and MT-COMP in this assay. Surprisingly, Ribo56 appeared to be more effective against MT-COMP (D469del) mRNA than WT-COMP mRNA, although the difference was not significant $(P=0.16)$ in this assay.

Western analysis was performed to assess MT-COMP protein knockdown by Ribo56 in the COS7 cells that were transfected with pMT-COMP and pRibo56 at concentrations 0 and $32 \times$. Protein was isolated 72 -h post-transfection. 

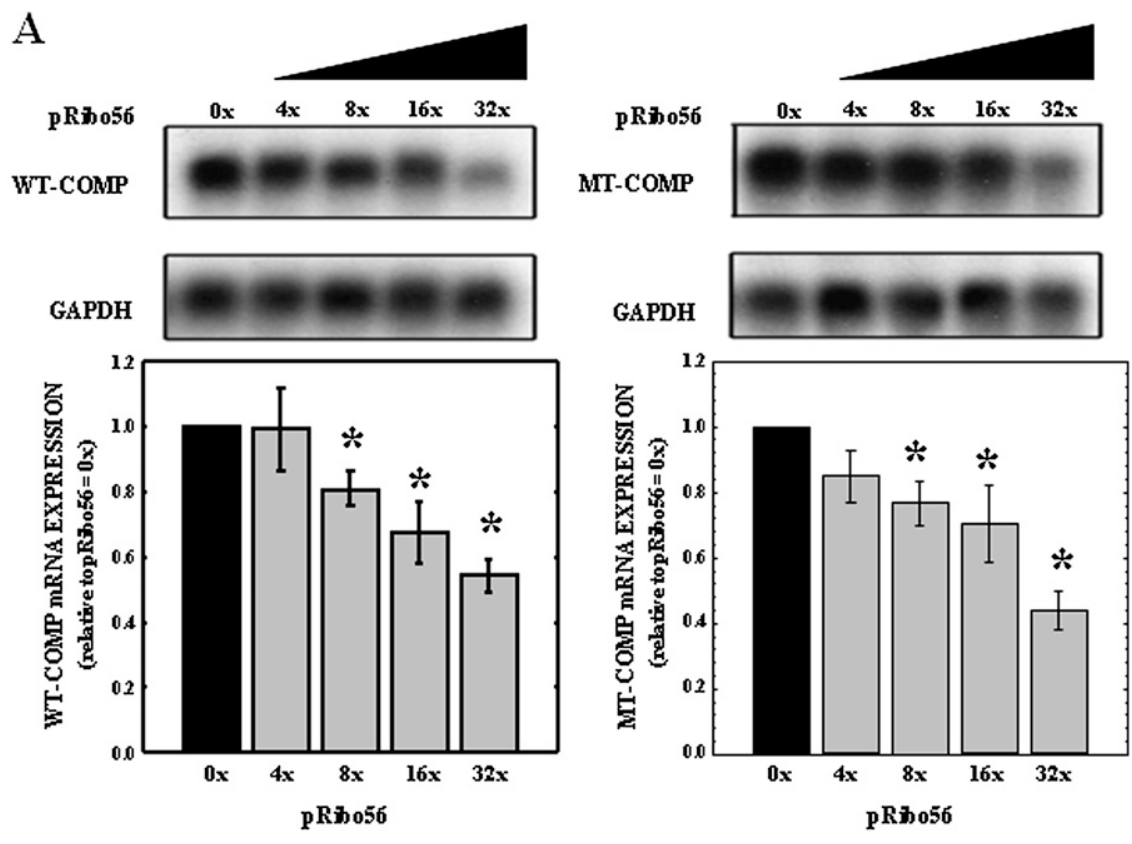

B

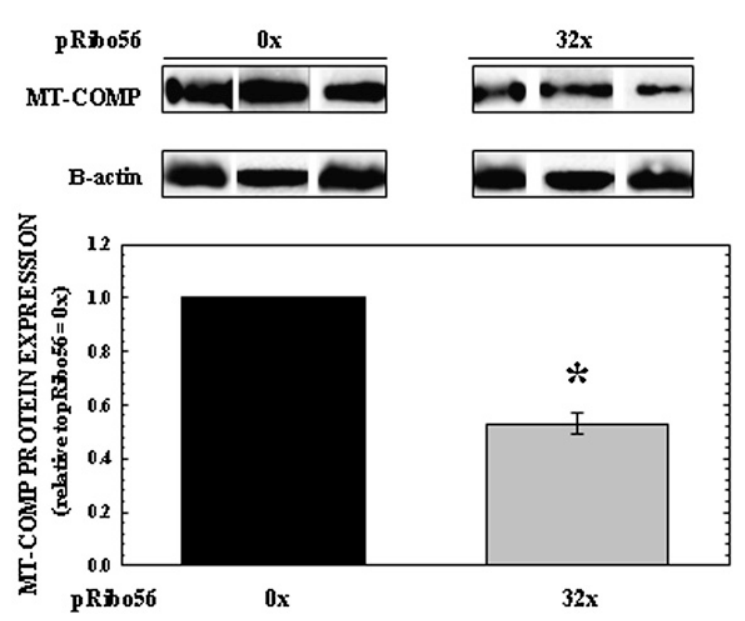

FIGURE 1. WT- and MT-COMP expression is decreased in a dose-dependent manner in COS7 cells cotransfected with increasing amounts of Ribo56 plasmid. COS7 cells were cotransfected with $250 \mathrm{ng}$ of either pWT-COMP or pMT-COMP and increasing amounts of pRibo56. RNA and cellular protein were harvested $72 \mathrm{~h}$ after transfection. (A) Total RNA (7 $\mu \mathrm{g}$ ) was subjected to Northern analysis using radiolabeled probes specific for COMP and human GAPDH (loading control). Representative autoradiographs $(\mathrm{N}=6)$ are shown above, while normalization of COMP mRNA knockdown is displayed in the bar graph. COS7 cells expressing only COMP $(0 \times)$ were normalized to 1 . Error bars represent the standard error of sample means $(\mathrm{SEM})$, and $P<0.05$ was considered significant $\left.{ }^{\star}\right)$. $(B)$ Protein $(30 \mu \mathrm{g})$ was subjected to Western analysis of three independent experiments with pMT-COMP using antibodies specific for COMP and $\beta$-actin (loading control). Shown are the resulting autoradiographs and bar graph normalization of the results.

The results of three independent transfections are shown in Figure 1B. Quantification of intracellular MT-COMP protein shows that, in the presence of Ribo56 at a concentration of $32 \times$, COMP was significantly reduced by $45 \%$. These findings demonstrate that Ribo56 has the ability to reduce COMP protein levels in COS7 cells by reducing the steadystate levels of MT-COMP mRNA.
Dual adenovirus infection increases steady-state levels of COMP mRNA and protein in COS7 cells

The feasibility of a recombinant adenovirus system to deliver Ribo56 to cells was assessed in COS7 cells. COS7 cells were coinfected at a constant multiplicity of infection (MOI) of a recombinant adenovirus that expressed either WTCOMP (AdWT) or MT-COMP (AdMT) with an increasing MOI $(0-32 \times)$ of a recombinant adenovirus expressing Ribo56 (AdRibo56). Infected cells were incubated for $96 \mathrm{~h}$, and the RNA was isolated. Northern analysis showed that neither WT- nor MT-COMP mRNAs decreased in the presence of increasing Ribo56 in these cells (Fig. 2A). In fact, steady-state COMP mRNA levels increased with increasing MOI of AdRibo56 (Fig. 2A). This increase also was reflected in the steady-state levels of WT- and MT-COMP protein (Fig. 2B). Surprisingly, the coinfection unexpectantly appeared to increase steady-state levels of COMP mRNA and protein.

To assess whether the increase of COMP mRNA was due to increased Ribo56 or adenovirus, the experiment was repeated using increasing AdGFP with constant AdWT- or AdMT-COMP. The results in Figure 3 show that the expression of both WT- and MT-COMP mRNA increases in the presence of an increasing amount of AdGFP. These data suggest that increasing adenovirus infection leads to activation of the CMV promoter driving COMP expression. Therefore, the dual infection approach for disease modeling was abandoned.

\section{Expression of endogenous COMP mRNA is decreased in a dose- dependent manner in primary human chondrocytes (hCCCs) infected with increasing MOls of AdRibo56}

Previous experiments suggested that adenoviral delivery of genes to hCCCs can be efficiently undertaken (Merritt et al. 2006). However, the coinfection results described above suggest that in the presence of two different adenoviruses, one encoding the target and one encoding the ribozyme, there are unexpected interactions that lead to an overall increase in the levels of COMP (Fig. 2). To determine 
whether this was an artifact of cotransfection of two viral expression vectors, studies were undertaken to investigate the knockdown of endogenous COMP in hCCCs. The
hCCCs were infected with increasing MOIs of AdRibo56 ranging from 0 to 200 . RNA was isolated 96 -h post-infection and subjected to Northern analysis. As shown in Figure 4,
A
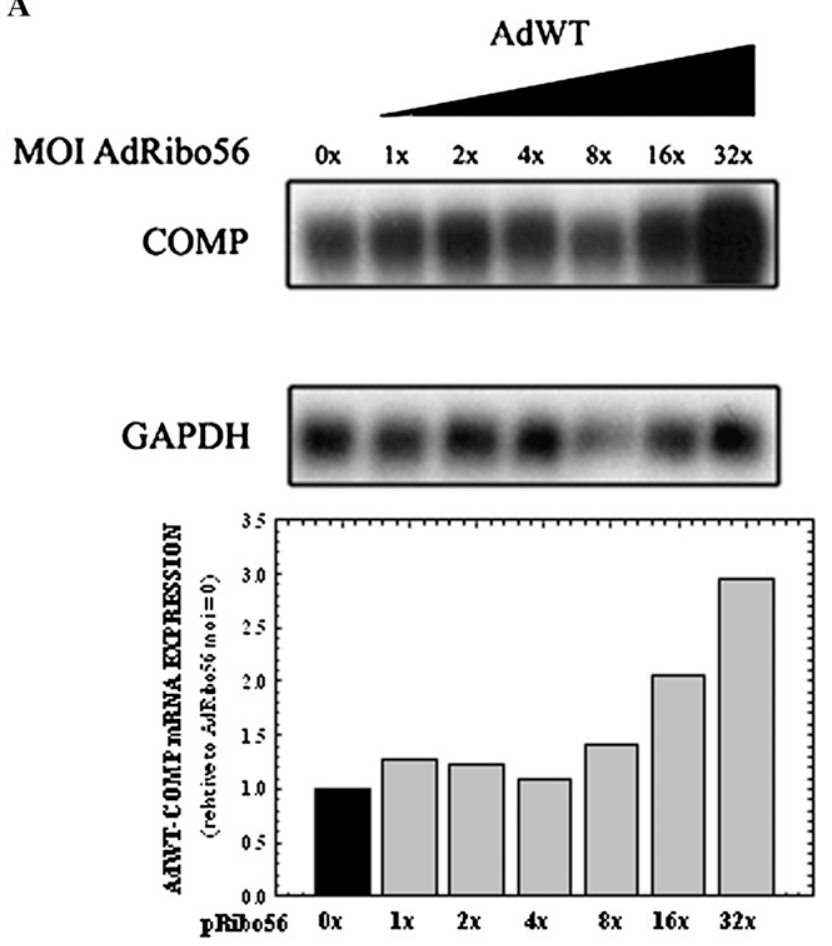

B
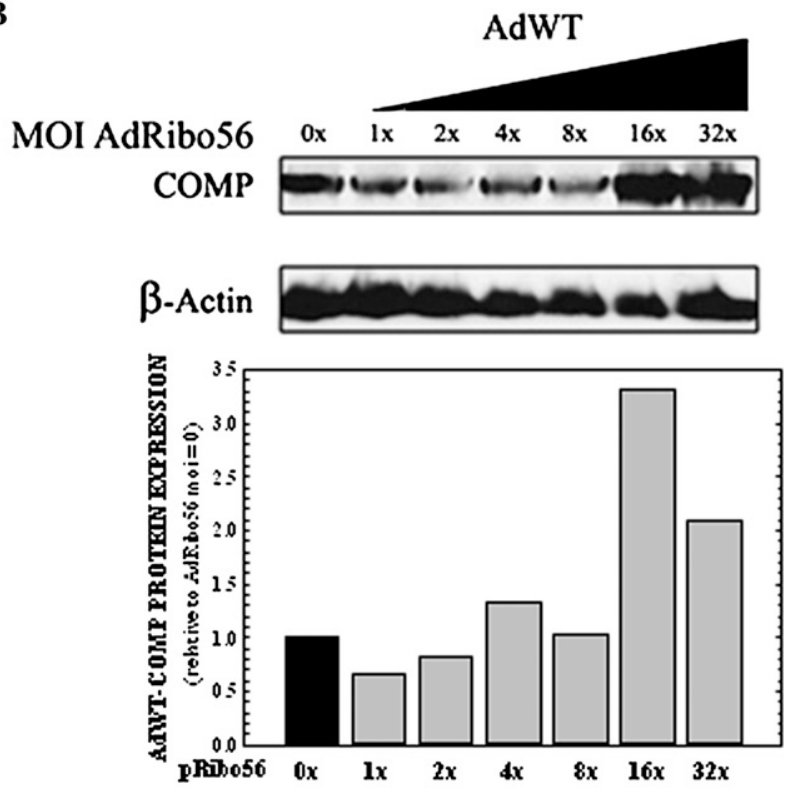
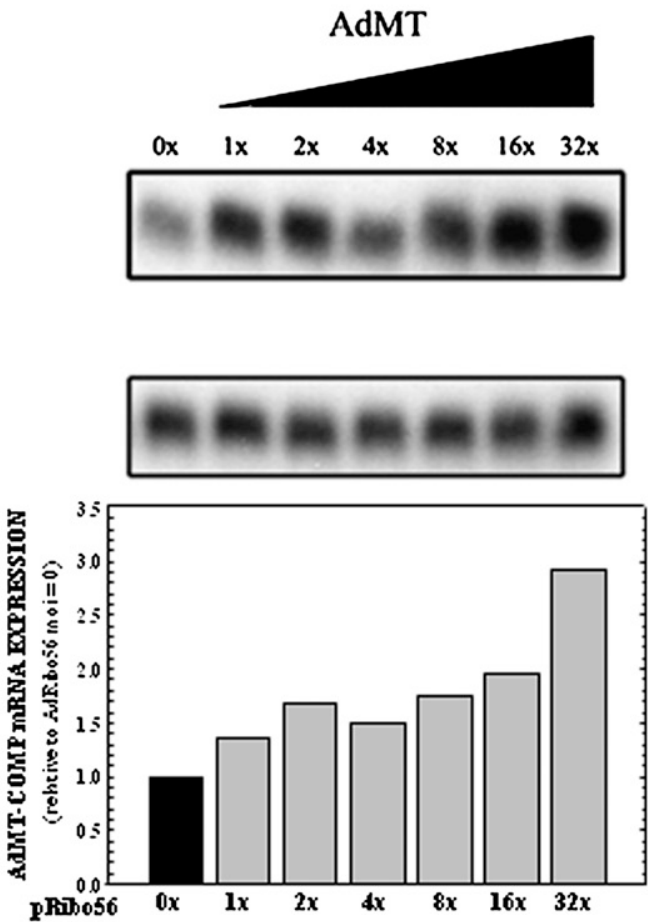
A

B
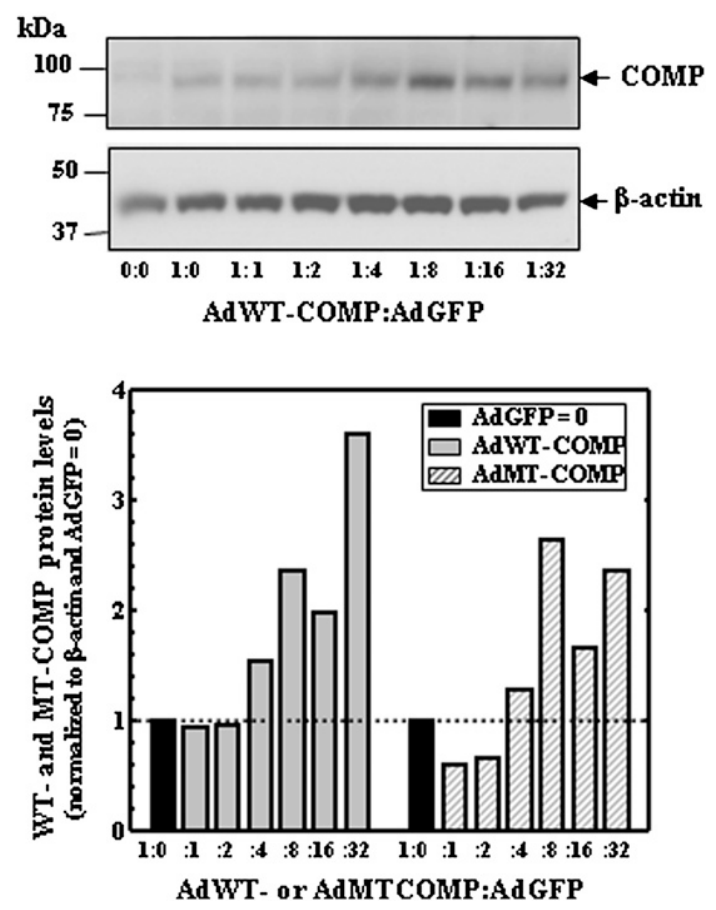

FIGURE 3. Adenovirus-based COMP expression is increased in COS7 cells when coinfected with adenovirus expressing only GFP. COS7 cells were coinfected with either AdWT- or AdMT-COMP with an increasing MOI of AdGFP. Cellular proteins were collected after 96 h. (A) Protein $(30 \mu \mathrm{g})$ from AdWT-COMP:AdGFP was subjected to Western analysis using antibodies specific for FLAG and $\beta$-actin (loading control) and visualized by ECL. Resulting autoradiographs are shown. (B) Normalized COMP protein from AdWT- or MTCOMP:AdGFP is shown in the bar graph. COS7 cells expressing only $\operatorname{COMP}(0 \times)$ were normalized to 1 .

the presence of AdRibo56 significantly $(P<0.05)$ decreased endogenous steady-state normal COMP mRNA levels in the hCCCs at the highest MOIs. As the AdRibo56 MOI increased to 100, dose-dependent knockdown was observed; endogenous COMP mRNA expression was reduced by $47 \%$ for AdRibo56 at an MOI of 100.

\section{AdRibo56 reduces COMP mRNA expression in primary mutant PSACH chondrocytes with three different COMP mutations more efficiently than in normal chondrocytes}

Results shown in Figure 4 indicated that the adenovirus delivery system can be used to knock down endogenous WT-COMP in primary hCCCs. The next series of experiments were performed to determine whether AdRibo56 reduces COMP mRNA levels in three primary PSACH chondrocytes with G427E, D469del, or D511Y COMP mutations and to compare the extent of knockdown to that of the normal COMP. Mutant chondrocytes were infected with AdRibo56 at MOIs of 0, 50, 75, and 100. As seen in Figure 5, Northern analysis of mRNA from these cells shows a reduction in the steady-state COMP with increasing MOIs of AdRibo56 for all PSACH mutations. Quantification shows that at all MOIs greater than 50, AdRibo56 significantly reduced the WT- and to a greater extent the MT-COMP mRNA levels. The D469del mRNA was maximally reduced by $73 \%$ at an MOI of 75 , the G427 and D511Y mRNAs were maximally reduced by $70 \%$ and $77 \%$, respectively, at an MOI of 100 . These results indicate that Ribo56 is very effective at reducing steady-state levels of MT-COMP for all three mutations but specifically appears more effective against D469del MT-COMP at lower MOIs. These data indicate that Ribo56 is more effective against MT-COMP compared with endogenous WT-COMP when expressed in chondrocytes (Fig. 5).

\section{DISCUSSION}

This is the first report to show reduction of COMP using a ribozyme that is amenable to use in future gene therapy applications for patients suffering from COMP-related skeletal dysplasias. Ribo56, a hammerhead ribozyme directed against the COMP sequence, targets the GUC triplet near nucleotide 56 of the mature mRNA and successfully reduces protein levels of both WT- and MTCOMP in chondrocytes. Most importantly, the ribozyme is more active in knockdown of three well-described MTCOMP species in chondrocytes when compared with normal WT-COMP (Fig. 4). Such preference presumably occurs because of differences in the secondary structure (Andronescu et al. 2005) or accessibility of target sequences in ribonucleoprotein complexes (Welting et al. 2008) of the transcripts encoding wild-type versus mutant COMP. Selective targeting of mutant COMP over WT-COMP by a ribozyme has never been reported.

In the initial phases of this study, COS7 cells were used as an in vitro model because the cells are easily transfected and, importantly, they do not synthesize COMP or any other ECM protein that might potentially interfere with the outcome (Hashimoto et al. 2003). Therefore, these studies directly tested the ability of Ribo56 to knock down either WT- or MT-COMP mRNA and protein without competition from endogenous COMP. Transfected cells can take up more than one type of plasmid efficiently, eliminating the possibility of singly transfected cells and allowing dosedependent assessment of the ribozyme. The results clearly demonstrate that Ribo56 significantly reduced COMP mRNA at most concentrations $(8 \times-32 \times)$ but was most effective at the highest concentration $(32 \times)$. Under these conditions, when both target and ribozyme were expressed from a plasmid, Ribo56 reduced WT- or MT-COMP equally. In these studies, MT-COMP mRNA was reduced by at least $50 \%$ and protein levels by $45 \%$. These results indicate that COMP mRNA knockdown is reflected in the reduction of COMP protein levels in this model system. 


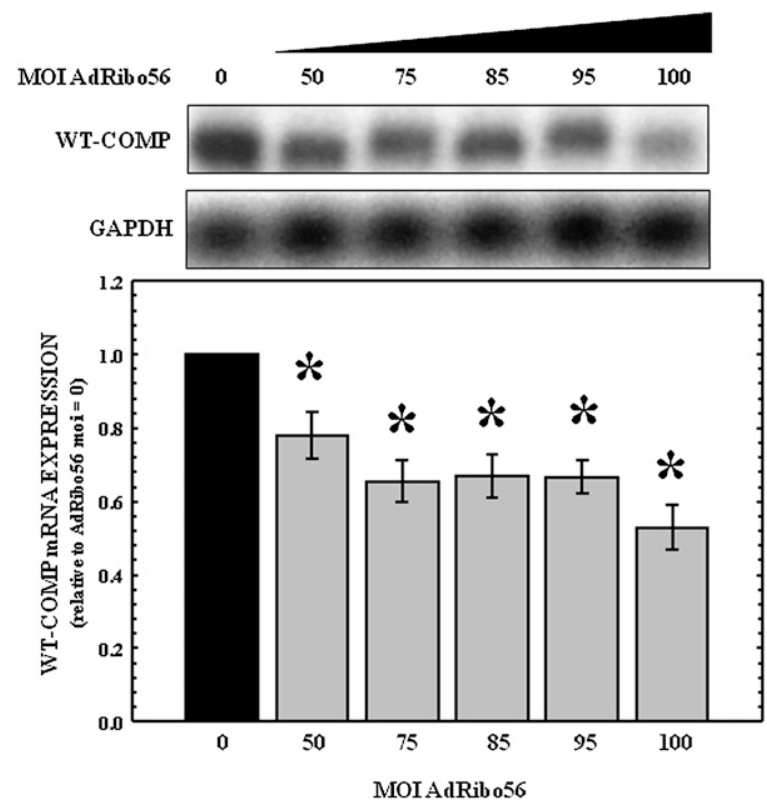

FIGURE 4. Expression of MT-COMP mRNA is decreased in a dosedependent manner in primary hCCCs infected with increasing MOIs of adenovirus expressing Ribo56. Normal costochondral chondrocytes were isolated as previously described and were transfected in monolayer with an increasing MOI of AdRibo56 (shown above the gel). RNA was collected after $96 \mathrm{~h}$. Total RNA $(7 \mu \mathrm{g})$ was subjected to Northern analysis using radiolabeled probes specific for COMP and human GAPDH (loading control). Representative autoradiographs $(\mathrm{N}=5)$ are shown above, and COMP expression in uninfected cells was used to normalize to 1 . Error bars represent the SEM, and $P<$ 0.05 was considered significant $\left(^{*}\right)$.

Recombinant adenovirus has been used to successfully transfect a wide variety of primary and transformed cells and hCCCs, in particular (Wickham et al. 1996; Merritt et al. 2006). Therefore, recombinant adenovirus technology was used to deliver AdRibo56 in the next series of studies. Coinfection of WT- and MT-COMP into COS7 cells in the presence of Ribo56 first was performed to assess the effectiveness of adenovirally delivered ribozyme against overexpressed COMP (James and Turner 1997; Tabler and Sczakiel 1997; Merritt et al. 2006) in these cells. Surprisingly, coinfection resulted in a net increase of both WT- and MT-COMP mRNA and protein. This increase in steady-state levels of COMP could be the result of interactions of gene products of the two independent adenoviruses that alter transcript processing, export, or stability or increase gene expression in unanticipated ways (Timpe et al. 2006). Alternatively, Ribo56 is not able to recognize or cleave the target sequence when both are expressed from an adenovirus. Interestingly, when the COMP adenovirus MOI was reduced even further, the increase in steady-state levels of COMP still occurred in the presence of the ribozyme but only when it was delivered using an adenoviral vector (data not shown). This finding may suggest that cellular stress from the presence of two separate adenoviral vectors may stimulate COMP expression.
The disease pathology in PSACH is specific for the growth plate chondrocytes (Cooper et al. 1973; Hecht et al. 1998b; Hecht et al. 2004, 2005). Therefore, a system with the capacity to deliver the ribozyme sequence into these cells must be obtained. To eliminate the complications of synergistic effects on ribozyme activity from two different adenoviruses and to test the function of Ribo56 in a more native system, hCCCs were infected with different MOIs of adRibo56 to determine the effect of the ribozyme on endogenous COMP. As seen in Figure 3, steady-state WT-COMP mRNA levels were reduced by Ribo56 in a dose-dependent manner up to $50 \%$ at the highest concentrations. The same approach was used to test the effectiveness of Ribo56 against MT-COMP in three different PSACH patient hCCCs. The results shown in Figure 4 clearly show that COMP mRNA expression was reduced by $\sim 70 \%$ for D468del, G427E, and D511Y mutations. The magnitude of the reduction suggests that this ribozyme may be more effective against MT-COMP than WT-COMP in native chondrocytes. The difference in efficiency of mRNA cleavage may be related to the difference in folding patterns of the WT-COMP mRNA compared with the MTCOMP (Fedor and Uhlenbeck 1990; Liu et al. 2000; Liu et al. 2002). Even though the site of cleavage of Ribo56 is near the $5^{\prime}$ end of the COMP transcript, the changes in the secondary structures of MT-COMP compared with WTCOMP assessed by S-fold extend to the region complementary to the annealing arms of the ribozyme. Of interest, the preference of the ribozyme for the mutant transcript over the native one may selectively reduce the levels of the mutant rather than the native form of COMP when both coexist in PSACH chondrocytes (Merritt et al. 2006).

Mutations in COMP cause the PSACH and MED (EMD1 type) skeletal dysplasias. The disease pathology of these conditions results from the massive retention of misfolded COMP and inappropriate formation of intracellular matrix in the rER (Merritt et al. 2007). In contrast, COMP null mice are normal, suggesting that loss of COMP does not compromise normal growth, development, or longevity. Thus, a treatment strategy removing or reducing steady-state levels of mutant COMP in chondrocytes of affected individuals is needed. Here, we show that Ribo56 can reduce COMP mRNA and protein with a preference for knocking down the mutant form. This opens the door for the use of mutant-recognizing ribozymes as an effective gene therapy for these skeletal dysplasias.

\section{MATERIALS AND METHODS}

\section{Cell culture}

Cells (hCCCs) were obtained from patients undergoing pectus excavatum surgery after informed consent at Shriners Hospital for Children-Houston (Hecht et al. 1998b, 2004). hCCCs were cultured as described above in $20 \%$ fetal bovine serum (FBS). 



FIGURE 5. COMP mRNA expression is decreased in a dosedependent manner in primary PSACH chondrocytes with three different COMP mutations infected with increasing MOIs of adenovirus expressing Ribo56. PSACH chondrocytes heterozygous for WT COMP and one of three COMP mutations (D469del, G427E, or $\mathrm{D} 511 \mathrm{Y}$ ) were isolated as previously described and were infected with increasing MOIs of AdRibo56. RNA was collected after $96 \mathrm{~h}$. Total RNA $(7 \mu \mathrm{g})$ was subjected to Northern analysis using radiolabeled probes specific for COMP and human GAPDH (loading control). Representative autoradiographs $(\mathrm{N}=3)$ are shown above, while normalization of COMP mRNA knockdown is displayed in the bar graph. COMP expression in uninfected cells $(0 \times)$ was normalized to 1. Error bars represent the SEM, and $P<0.05$ was considered significant. $\left(^{*}\right) P \leq 0.01$ versus wild type; (\#) $P \leq 0.01$ versus D469del; $(\S) P \leq 0.01$ versus G427E.

Two PSACH patient chondrocyte lines, D469del (deletion of aspartic acid 469) and G427E, were obtained from the Iowa skeletal dysplasia cell bank (Hecht et al. 1998b). The third PSACH patient cell line, D511Y, was obtained from a growth plate biopsy (Hecht et al. 2005). All of the chondrocyte samples were from prepubertal children. These three PSACH cell lines were heterozygous for the COMP mutations. Normal growth plate chondrocytes were isolated as previously described (Hecht et al. 2004).

\section{Hammerhead ribozyme vectors}

The hammerhead ribozyme (Ribo56) and annealing arms were designed using the methods previously described (Liu et al. 2002) and its target sequence validated using S-ribo (http://sfold.wadsworth. org/sribo.pl). S-fold was used to compare the predicted secondary structures for normal and three mutant COMP sequences chosen for this study, all of which affected the predicted folding pattern of the target transcripts in a manner that could impact interactions with targeted ribozymes. Ribozyme 56 cuts at nucleotide 56 of the COMP mRNA: 5'-CUGCCCUCGGCGCGUCCGGACAGGGCC AG-3'. The cut site (underlined) lies in the region of the transcript encoding the $\mathrm{C}$-terminal half of the signal sequence extending just into the coding sequence for the mature protein. Hence, blockade or cleavage of this region will reduce transcript levels when cut and interfere with translation of the key portion of the molecule governing entry into the secretory pathway when functioning as an antisense molecule. DNA encoding the hammerhead ribozyme first was ligated into the BLOCK-iT U6 RNAi entry vector of the ViraPower Lentiviral Gateway expression system (Invitrogen). The Ribo56 construct includes a U6 promoter sequence, the small nuclear RNA (snRNA) U1 sequence for stabilization of the ribozyme and a Pol III termination sequence. To generate the AdRibo56, the expression cassette was excised from the original vector and ligated into the multiple cloning site of the pAdTrackGFP shuttle vector (Qbiogene). AdRibo56 was expanded to working titers by Vector Biolabs.

Two COMP expression plasmid vectors were provided by Dr. Jeff W. Stevens (University of Iowa) (Chen et al. 2004). These pcDNA3.1+ vectors contain either a WT-COMP (GenBank accession number: L32137) or MT-COMP (D469del) that have a FLAG tag amino acid sequence (DYKDDDDK) added to the carboxyl terminus. The recombinant adenoviruses (AdWT and AdMT) were constructed as previously described (Merritt et al. 2006) and expanded to working titers by Vector Biolabs.

\section{Plasmid transfection}

COS7 cells were cultured in 6-well tissue culture dishes and grown to $80 \%-90 \%$ confluency. Cells were transfected per manufacturer's instructions with plasmid DNA using a 3:2 ratio of FuGene6 (Roche) to plasmid DNA. All transfections contained $250 \mathrm{ng}$ of WT- or MT-COMP plasmid and were cotransfected with varying amounts of Ribo56 and pUC18 plasmids for a total of $8.25 \mu \mathrm{g}$ DNA per transfection to obtain steady-state COMP plasmid with an increasing concentration of Ribo56 plasmid (Table 1). The COS7 cells were transfected and incubated for 96 h. The cells were collected at $96 \mathrm{~h}$ using either Trizol (Invitrogen) for RNA or, for protein, RIPA buffer (50 mM Tris at $\mathrm{pH} 7.4,150$ $\mathrm{mM} \mathrm{NaCl}, 2 \mathrm{mM}$ EDTA, $1 \%$ [v/v] Triton X-100, Mini complete protease inhibitors [Roche]; $1 \%$ [v/v] Na-deoxycholate; $0.1 \%$ [v/v] SDS).

\section{Viral transfection}

The hCCCs were cultured in monolayer in T25 flasks and infected for $18 \mathrm{~h}$ in serum-free Dulbecco's modified Eagle medium (DMEM) with AdRibo56 at MOIs of 0, 50, 75, 85, 95, 100, 110, 150 , and 200. PSACH patient chondrocytes were infected using MOIs of $0,50,75$, and 100 . The medium was replaced with $\mathrm{DMEM}+20 \% \mathrm{FBS}$ and $1 \% \mathrm{Ab} / \mathrm{Am}$ and cells were incubated at $37^{\circ} \mathrm{C}$ for a total of $96 \mathrm{~h}$. COS7 cells were cultured in 6-well tissue culture dishes and grown to confluency. Cells then were infected for $18 \mathrm{~h}$ using $1.5 \mathrm{~mL}$ of serum-free DMEM containing either AdWT- or AdMT-COMP at an MOI of 1 and AdR56 with 
TABLE 1. Ratios of plasmid transfected into COS7 cells

\begin{tabular}{lccc}
\hline & $\begin{array}{c}\text { WT-/MT-COMP } \\
\text { plasmid } \\
(\mathrm{ng})\end{array}$ & $\begin{array}{c}\text { puc18 } \\
\text { plasmid } \\
(\mu \mathrm{g})\end{array}$ & $\begin{array}{c}\text { Ribo56 } \\
\text { plasmid }\end{array}$ \\
\hline Control & 0 & 0 & 0 \\
$0 \times$ & 250 & 8 & 0 \\
$4 \times$ & 250 & 7 & 1 \\
$8 \times$ & 250 & 6 & 2 \\
$16 \times$ & 250 & 4 & 4 \\
$32 \times$ & 250 & 0 & 8 \\
\hline
\end{tabular}

increasing MOIs to give a ratio of $0 \times$ to $32 \times$. The medium was replaced with DMEM + 10\% FBS and $1 \% \mathrm{Ab} / \mathrm{Am}$.

\section{RNA isolation and purification from cultured cells}

RNA was isolated from both plasmid and viral transfected COS7 cells and hCCCs after 72 or $96 \mathrm{~h}$ using $3 \mathrm{~mL}$ (for 6-well) or $4 \mathrm{~mL}$ (T25 flask) of Trizol. The Trizol-cell mixture then was processed using the PureLink Micro- to Midi-RNA isolation kit (Invitrogen) following the manufacturer's protocol. The RNA was quantitated using a NanoDrop spectrophotomer (Thermo Fisher Scientific). Purified samples were stored at $-80^{\circ} \mathrm{C}$.

\section{Northern analysis}

Northern analysis was performed as described in Sambrook and Russell (2001). A radioactive probe was made using the Stratagene Prime-It RmT Random primer labeling kit following the manufacturer's protocol. The DNA templates were made from COMP cDNA excised from a pcDNA3.1+ vector and gel purified using the Qiaquick gel extraction kit (Qiagen) following the manufacturer's protocol. Human glyceraldehyde-3-phosphate dehydrogenase (GAPDH) template obtained from Origene (GenBank: NM_002046) was excised and gel purified as described above. The radioactive probe was hybridized at $55^{\circ} \mathrm{C}$ overnight. The washed membrane was sealed and exposed to X-ray film. Films were scanned and processed by the software GeneSnap (Syngene) and analyzed for densitometry using the GeneTools software (Syngene).

\section{Protein isolation and Western analysis}

Protein was isolated from transfected COS7 cells and chondrocytes by using $500 \mu \mathrm{l}$ (for 6-well) or $1 \mathrm{~mL}$ (T25 flask) of RIPA buffer. Western analysis was performed as described in Sambrook and Russell (2001). Total protein $(30 \mu \mathrm{g})$ was electrophoresed through a NuPAGE $10 \%(\mathrm{w} / \mathrm{v})$ Bis-Tris gel (Invitrogen). The gel was transferred to a polyvinylidene fluoride (PVDF) membrane (Millipore). The membrane was incubated with primary rabbit (rab) polyclonal antibody for COMP $(1: 10,000)$ (Kamiya Biomedical) or the FLAG epitope (1:5,000) (Sigma Chemical Co) and incubated with horseradish peroxidase (HRP) goat anti-rabbit IgG $(1: 7,500)$ (GE Healthcare). To ensure uniform loading, $\beta$-actin levels were determined with a $\beta$-actin rabbit primary conjugated with HRP $(1: 75,000)$ (Abcam). Visualization of the complex was accomplished using the ECL Plus kit (GE Healthcare) following the manufacturer's protocol. Films were scanned and processed using GeneSnap (Syngene) and analyzed for densitometry using GeneTools software (Syngene).

\section{Statistical analysis}

The results of each replicate experiment were compared for each concentration of Ribo56 by dividing the pixel score of COMP by the pixel score of GAPDH (RNA) or $\beta$-actin (protein) for the corresponding lane (data not shown). A two-tailed t-test $(P<$ 0.05) was used to assess the differences between the COMP mRNA levels and the protein levels for the different experiments for each concentration ratio by comparing them individually to the control COMP levels. The control COMP mRNA levels and protein levels were normalized to a density value of 1 , and the mean value was established in comparison for each Ribo56 concentration and displayed in a bar graph. All error bars represent the standard error of sample means (SEM). Asterisk $\left(^{*}\right)$ denotes mean values that are significantly $(P$-value $<0.05)$ different from the control.

\section{ACKNOWLEDGMENTS}

This study was supported by grants from NIH HL68116 (J.L.A.), NIH P20RR016458 (M.C.F.-C.), Shriners Hospital for Children (J.T.H.), and the Leah Lewis Family Foundation (J.T.H.). We thank Drs. Shea Posey and S. Shahrukh Hashmi for helpful suggestions.

Received August 28, 2008; accepted December 23, 2008.

\section{REFERENCES}

Adams, J., Tucker, R.P., and Lawler, J. 1995. The thrombospondin gene family. Springer, New York.

Andronescu, M., Zhang, Z.C., and Condon, A. 2005. Secondary structure prediction of interacting RNA molecules. J. Mol. Biol. 345: 987-1001.

Blount, K.F. and Uhlenbeck, O.C. 2002. The hammerhead ribozyme. Biochem. Soc. Trans. 30: 1119-1122.

Briggs, M.D. and Chapman, K.L. 2002. Pseudoachondroplasia and multiple epiphyseal dysplasia: Mutation review, molecular interactions, and genotype to phenotype correlations. Hum. Mutat. 19: 465-478.

Briggs, M.D., Hoffman, S.M., King, L.M., Olsen, A.S., Mohrenweiser, H., Leroy, J.G., Mortier, G.R., Rimoin, D.L., Lachman, R.S., Gaines, E.S., et al. 1995. Pseudoachondroplasia and multiple epiphyseal dysplasia due to mutations in the cartilage oligomeric matrix protein gene. Nat. Genet. 10: 330-336.

Cameron, F.H. and Jennings, P.A. 1989. Specific gene suppression by engineered ribozymes in monkey cells. Proc. Natl. Acad. Sci. 86: 9139-9143.

Carlson, C.B., Lawler, J., and Mosher, D.F. 2008. Structures of thrombospondins. Cell. Mol. Life Sci. 65: 672-686.

Chen, T.L., Stevens, J.W., Cole, W.G., Hecht, J.T., and Vertel, B.M. 2004. Cell-type specific trafficking of expressed mutant COMP in a cell culture model for PSACH. Matrix Biol. 23: 433-444.

Chen, F.H., Thomas, A.O., Hecht, J.T., Goldring, M.B., and Lawler, J. 2005. Cartilage oligomeric matrix protein/thrombospondin 5 supports chondrocyte attachment through interaction with integrins. J. Biol. Chem. 280: 32655-32661.

Cooper, R.R., Ponseti, I.V., and Maynard, J.A. 1973. Pseudoachondroplasia dwarfism. A rough-surfaced endoplasmic reticulum disorder. J. Bone Joint Surg. Am. 55A: 475-484. 
DiCesare, P., Hauser, N., Lehman, D., Pasumarti, S., and Paulsson, M. 1994. Cartilage oligomeric matrix protein (COMP) is an abundant component of tendon. FEBS Lett. 354: 237-240.

Duke, J., Montufar-Solis, D., Underwood, S., Lalani, Z., and Hecht, J.T. 2003. Apoptosis staining in cultured pseudoachondroplasia chondrocytes. Apoptosis 8: 191-197.

Fedor, M.J. and Uhlenbeck, O.C. 1990. Substrate sequence effects on "hammerhead" RNA catalytic efficiency. Proc. Natl. Acad. Sci. 87: $1668-1672$.

Fife, R.S. and Brandt, K.D. 1984. Identification of a high-molecularweight $(>400,000)$ protein in hyaline cartilage. Biochim. Biophys. Acta 802: 506-514.

Haseloff, J. and Gerlach, W.L. 1988. Simple RNA enzymes with new and highly specific endoribonuclease activities. Nature 334: 585591.

Haseloff, J. and Gerlach, W.L. 1992. Simple RNA enzymes with new and highly specific endoribonuclease activities. 1988. Biotechnology 24: $264-269$.

Hashimoto, Y., Tomiyama, T., Yamano, Y., and Mori, H. 2003. Mutation (D472Y) in the type 3 repeat domain of cartilage oligomeric matrix protein affects its early vesicle trafficking in endoplasmic reticulum and induces apoptosis. Am. J. Pathol. 163: 101-110.

Hecht, J.T., Nelson, L.D., Crowder, E., Wang, Y., Elder, F.F., Harrison, W.R., Francomano, C.A., Prange, C.K., Lennon, G.G., Deere, M., et al. 1995. Mutations in exon 17B of cartilage oligomeric matrix protein (COMP) cause pseudoachondroplasia. Nat. Genet. 10: 325-329.

Hecht, J.T., Deere, M., Putnam, E., Cole, W., Vertel, B., Chen, H., and Lawler, J. 1998a. Characterization of cartilage oligomeric matrix protein (COMP) in human normal and pseudoachondroplasia musculoskeletal tissues. Matrix Biol. 17: 269-278.

Hecht, J.T., Montufar-Solis, D., Decker, G., Lawler, J., Daniels, K., and Duke, P.J. 1998b. Retention of cartilage oligomeric matrix protein (COMP) and cell death in redifferentiated pseudoachondroplasia chondrocytes. Matrix Biol. 17: 625-633.

Hecht, J.T., Makitie, O., Hayes, E., Haynes, R., Susic, M., MontufarSolis, D., Duke, P.J., and Cole, W.G. 2004. Chondrocyte cell death and intracellular distribution of COMP and type IX collagen in the pseudoachondroplasia growth plate. J. Orthop. Res. 22: 759-767.

Hecht, J.T., Hayes, E., Haynes, R., and Cole, W.G. 2005. COMP mutations, chondrocyte function and cartilage matrix. Matrix Biol. 23: 525-533.

Hendry, P., McCall, M.J., and Lockett, T.J. 1997. Design of hybridizing arms in hammerhead ribozymes. In Ribozyme protocols (ed. P.C. Turner), pp. 254-264. Humana Press, Totowa, NJ.

Holden, P., Meadows, R.S., Chapman, K.L., Grant, M.E., Kadler, K.E., and Briggs, M.D. 2001. Cartilage oligomeric matrix protein interacts with type IX collagen, and disruptions to these interactions identify a pathogenetic mechanism in a bone dysplasia family. J. Biol. Chem. 276: 6046-6055.

James, H.A. and Turner, P.C. 1997. Ribozymes. In Ribozyme Protocols (ed. P.C. Turner), pp. 1-9. Humana Press, Totowa, NJ.

Kempson, G.E., Freeman, M.A., and Swanson, S.A. 1968. Tensile properties of articular cartilage. Nature 220: 1127-1128.

Kennedy, J., Jackson, G.C., Barker, F.S., Nundlall, S., Bella, J., Wright, M.J., Mortier, G.R., Neas, K., Thompson, E., Elles, R., et al. 2005. Novel and recurrent mutations in the C-terminal domain of COMP cluster in two distinct regions and result in a spectrum of phenotypes within the pseudoachondroplasia-multiple epiphyseal dysplasia disease group. Hum. Mutat. 25: 593-594.

Khan, A.U. 2006. Ribozyme: A clinical tool. Clin. Chim. Acta 367: 20-27.

Kipnes, J., Carlberg, A.L., Loredo, G.A., Lawler, J., Tuan, R.S., and Hall, D.J. 2003. Effect of cartilage oligomeric matrix protein on mesenchymal chondrogenesis in vitro. Osteoarthritis Cartilage 11: 442-454.

Liu, R., Li, W., Karin, N.J., Bergh, J.J., Adler-Storthz, K., and FarachCarson, M.C. 2000. Ribozyme ablation demonstrates that the cardiac subtype of the voltage-sensitive calcium channel is the molecular transducer of 1, 25-dihydroxyvitamin $\mathrm{D}(3)$-stimulated calcium influx in osteoblastic cells. J. Biol. Chem. 275: 8711-8718.

Liu, R., Rohe, B., Carson, D.D., and Farach-Carson, M.C. 2002. A rapid and simple nonradioactive method for in vitro testing of ribozyme activity. Antisense Nucleic Acid Drug Dev. 12: 283-288.

Mann, H.H., Ozbek, S., Engel, J., Paulsson, M., and Wagener, R. 2004. Interactions between the cartilage oligomeric matrix protein and matrilins. Implications for matrix assembly and the pathogenesis of chondrodysplasias. J. Biol. Chem. 279: 25294-25298.

McCall, M.J., Hendry, P., and Jennings, P.A. 1992. Minimal sequence requirements for ribozyme activity. Proc. Natl. Acad. Sci. 89: 5710-5714.

Merritt, T.M., Alcorn, J.L., Haynes, R., and Hecht, J.T. 2006. Expression of mutant cartilage oligomeric matrix protein in human chondrocytes induces the pseudoachondroplasia phenotype. J. Orthop. Res. 24: 700-707.

Merritt, T.M., Bick, R., Poindexter, B.J., Alcorn, J.L., and Hecht, J.T. 2007. Unique matrix structure in the rough endoplasmic reticulum cisternae of pseudoachondroplasia chondrocytes. Am. J. Pathol. 170: 293-300.

Pirog-Garcia, K.A., Meadows, R.S., Knowles, L., Heinegard, D., Thornton, D.J., Kadler, K.E., Boot-Handford, R.P., and Briggs, M.D. 2007. Reduced cell proliferation and increased apoptosis are significant pathological mechanisms in a murine model of mild pseudoachondroplasia resulting from a mutation in the C-terminal domain of COMP. Hum. Mol. Genet. 16: 20722088.

Posey, K.L., Hayes, E., Haynes, R., and Hecht, J.T. 2004. Role of TSP5/COMP in Pseudoachondroplasia. Int. J. Biochem. Cell Biol. 36: $1005-1012$.

Posey, K.L., Yang, Y., Veerisetty, A.C., Sharan, S.K., and Hecht, J.T. 2008. Model systems for studying skeletal dysplasias caused by TSP-5/COMP mutations. Cell. Mol. Life Sci. 65: 687-699.

Rosenberg, K., Olsson, H., Morgelin, M., and Heinegard, D. 1998. Cartilage oligomeric matrix protein shows high affinity zincdependent interaction with triple helical collagen. J. Biol. Chem. 273: 20397-20403

Ruffner, D.E., Stormo, G.D., and Uhlenbeck, O.C. 1990. Sequence requirements of the hammerhead RNA self-cleavage reaction. Biochemistry 29: 10695-10702.

Sambrook, J. and Russell, D.W. 2001. Molecular cloning: A laboratory manual. Cold Spring Harbor Laboratory Press, Cold Spring Harbor, NY.

Schmidt, M.B., Mow, V.C., Chun, L.E., and Eyre, D.R. 1990. Effects of proteoglycan extraction on the tensile behavior of articular cartilage. J. Orthop. Res. 8: 353-363.

Schmitz, M., Niehoff, A., Miosge, N., Smyth, N., Paulsson, M., and Zaucke, F. 2007. Transgenic mice expressing D469Delta mutated cartilage oligomeric matrix protein (COMP) show growth plate abnormalities and sternal malformations. Matrix Biol. 27: 67-85.

Shimayama, T., Nishikawa, S., and Taira, K. 1995. Generality of the NUX rule: Kinetic analysis of the results of systematic mutations in the trinucleotide at the cleavage site of hammerhead ribozymes. Biochemistry 34: 3649-3654.

Shiota, M., Sano, M., Miyagishi, M., and Taira, K. 2004. Ribozymes: Applications to functional analysis and gene discovery. J. Biochem. 136: 133-147.

Smith, R.K., Zunino, L., Webbon, P.M., and Heinegard, D. 1997. The distribution of cartilage oligomeric matrix protein (COMP) in tendon and its variation with tendon site, age and load. Matrix Biol. 16: 255-271.

Svensson, L., Aszodi, A., Heinegard, D., Hunziker, E.B., Reinholt, F.P., Fassler, R., and Oldberg, A. 2002. Cartilage oligomeric matrix protein-deficient mice have normal skeletal development. Mol. Cell. Biol. 22: 4366-4371.

Tabler, M. and Sczakiel, G. 1997. Design and production of asymmetric hammerhead ribozymes. Methods Mol. Biol. 74: 141-149.

Thur, J., Rosenberg, K., Nitsche, D.P., Pihlajamaa, T., Ala-Kokko, L., Heinegard, D., Paulsson, M., and Maurer, P. 2001. Mutations in cartilage oligomeric matrix protein causing pseudoachondroplasia 
and multiple epiphyseal dysplasia affect binding of calcium and collagen I, II, and IX. J. Biol. Chem. 276: 6083-6092.

Timpe, J.M., Verrill, K.C., and Trempe, J.P. 2006. Effects of adenoassociated virus on adenovirus replication and gene expression during coinfection. J. Virol. 80: 7807-7815.

Unger, S. and Hecht, J.T. 2001. Pseudoachondroplasia and multiple epiphyseal dysplasia: New etiologic developments. Am. J. Med. Genet. 106: 244-250.

Urban, J.P., Maroudas, A., Bayliss, M.T., and Dillon, J. 1979. Swelling pressures of proteoglycans at the concentrations found in cartilaginous tissues. Biorheology 16: 447-464.

Welting, T.J., Mattijssen, S., Peters, F.M., van Doorn, N.L., Dekkers, L., van Venrooij, W.J., Heus, H.A., Bonafe, L., and
Pruijn, G.J. 2008. Cartilage-hair hypoplasia-associated mutations in the RNase MRP P3 domain affect RNA folding and ribonucleoprotein assembly. Biochim. Biophys. Acta 1783: 455-466.

Wickham, T.J., Roelvink, P.W., Brough, D.E., and Kovesdi, I. 1996. Adenovirus targeted to heparin-containing receptors increases its gene delivery efficiency to multiple cells. Nat. Biotechnol. 14: 15701573.

Xu, K., Zhang, Y., Ilalov, K., Carlson, C.S., Feng, J.Q., Di Cesare, P.E., and Liu, C.J. 2007. Cartilage oligomeric matrix protein associates with granulin-epithelin precursor (GEP) and potentiates GEPstimulated chondrocyte proliferation. J. Biol. Chem. 282: 1134711355. 

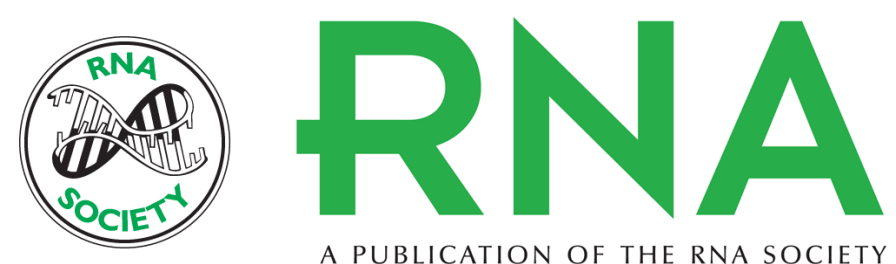

A PUBLICATION OF THE RNA SOCIETY

\section{Ribozyme-mediated reduction of wild-type and mutant cartilage oligomeric matrix protein (COMP) MRNA and protein}

Joseph L. Alcorn, Thomas M. Merritt, Mary C. Farach-Carson, et al.

RNA 2009 15: 686-695 originally published online February 23, 2009

Access the most recent version at doi:10.1261/rna.1335909

\section{References This article cites 51 articles, 12 of which can be accessed free at: http://rnajournal.cshlp.org/content/15/4/686.full.html\#ref-list-1}

\section{License}
Email Alerting Receive free email alerts when new articles cite this article - sign up in the box at the Service top right corner of the article or click here.

